\title{
Plasma sprayed hydroxy apatite coatings ${ }^{\dagger}$
}

\author{
D S PATIL, K P SREEKUMAR, N VENKATARAMANI, R K IYER*, \\ RAM PRASAD**, R S KOPPIKAR*** and K R MUNIM**** \\ Laser and Plasma Technology Division, *Applied Chemistry Division, ${ }^{* *}$ Metallurgy \\ Division, ${ }^{* * *}$ Centra! Workshops, ${ }^{* * * *}$ Medical Division, Bhabha Atomic Research Centre, \\ Bombay 400085 , India
}

\begin{abstract}
This paper describes the method of producing plasma sprayed coatings of hydroxy apatite (HA) on metaliic substrates of Ti-6Al-4V. Hydroxy apatite is a material which has similar composition to that of the mineral phase of the human bone. Poor mechanical properties however inhibits its use in the load bearing applications. The powders prepared in our laboratory are sprayed using a plasma spray torch operating in ambient. The deposited coatings are characterized by $\mathrm{X}$-ray diffraction and found to retain $\mathrm{HA}$ in the coatings as per requirements.
\end{abstract}

Keywords. Hydroxy apatite (HA); plasma spraying; coatings; bioceramics.

\section{Introduction}

The human bone consists of mainly two phases: one continuous phase of collagen and other proteins usually called the bone matrix and a discontinuous phase of very small crystals with structure of hydroxy apatite (HA). These HA crystals are embedded in the matrix. It is therefore not surprising that mineral HA has been considered as an implantable material to repair or augment the part of the skeleton. It is well known that the living bone shows a strong bond with implants made of sintered hydroxy apatite (De Groot 1981; Jarcho 1981). Devices made of HA materials are, therefore potentially least susceptible to rejection by the body. The biomechanical properties of sintered HA are poor. It has a compressive strength of $600-700 \mathrm{MPa}$ and a tensile strength of 200-250 MPa. The resistance against fatigue failure is very low. Normal physiological loading causes fatigue fracture of the dense HA tooth implants within several months. Therefore it can be safely concluded that HA implants can only be applied if either no force at all or only compressive forces act on the implant (De Groot 1981).

To get rid of these mechanical limitations it has been suggested to use thin coatings of $\mathrm{HA}$ on the metallic surfaces/substrates if the implant is going to be subjected to the tensile loading. Surface modification of the metallic implants by HA is the most promising means of combining the strength, ductility and ease of fabrication of metallic implants with increased biocompatibility and tissue growth afforded by HA (Stevenson et al 1989; Smith and Novak 1991). The coating is applied to a metallic substrate like Ti-6Al-4V to enhance the fixation of the implant to the osseous tissues. Coated implants can take on the characteristics of both metallic and ceramic materials. The advantage of $\mathrm{Ti}-6 \mathrm{Al}-4 \mathrm{~V}$ is that it is less susceptible to the corrosion than alloys such as 316 s.s and $\mathrm{Co}-\mathrm{Cr}$ alloys. It has lower elastic modulus, less dense and more compatible with the biological system. It has elastic modulus similar to that of the bone. Modulus

\footnotetext{
${ }^{\dagger}$ Paper presented at the poster session of MRSI AGM VI, Kharagpur, 1995.
} 
mismatch between $\mathrm{HA}$ and $\mathrm{Ti}-6 \mathrm{Al}-4 \mathrm{~V}$ being low, the strain at the coating substrate interface will be minimized when the prosthesis is stressed. Its light weight as compared to s.s and $\mathrm{Co}-\mathrm{Cr}$ based alloys would balance parts like hip etc. more evenly than s.s/Co-Cr alloys.

Coating thickness also plays an important role. Thinner the coating better is its mechanical properties (adhesion and tensile strength etc.). However, a $20 \mu \mathrm{m}$ of HA coating may dissolve in the first few months consequently defeating the purpose. A coating of thickness $>200 \mu \mathrm{m}$ can avoid dissolution by physiological solutions but potentially introduce fatigue failure under tensile loading. The required compromise leads to a thickness of around $50 \mu \mathrm{m}$. There is however some dispute in the open literature concerning the optimum thickness of bioceramic coatings, which are intended for orthopedic purposes. De Groot (1987a) proposed a limitation of $50 \mu \mathrm{m}$ whereas Osborn (1987) recommended $200 \mu \mathrm{m}$.

As per the earlier literature report on the biological properties of these coatings, it is observed that $\mathrm{HA}$ adheres strongly to the base. The tensile strength of such a bond is about 50-60 MPa, approximately equal to the strength of the bone itself. Other materials like Ti show hardly any bonding with the bone (tensile strength is hardly $0.6 \mathrm{MPa}$ ). However under certain conditions a direct bone contact may develop (De Groot 1987b).

Ceramic coatings are generally not directly deposited onto the substrates due to their brittle nature. Generally it is the practice for these coatings to be overlaid onto a thermally sprayed metal bond coat which act as a compliant layer between the substrate and the ceramic coating. However, no bond coat is required for spraying HA on $\mathrm{Ti}$. At elevated temperature of $800-1000^{\circ} \mathrm{C} \mathrm{HA}$ reacts with $\mathrm{TiO}_{2}$ which is always present on the Ti surface. At $1000^{\circ} \mathrm{C}$ it forms $\mathrm{CaTiO}_{3}$ and tricalcium phosphate (TCP). $\mathrm{CaTiO}_{3}$ formed acts as a bond layer and hence adhesion is much stronger (60 MPa) than bonding mechanisms which rely on the mechanical interlocking. Conditions encountered during plasma spraying may initiate such a reaction as well.

$$
\begin{aligned}
\mathrm{Ca}_{10}\left(\mathrm{PO}_{4}\right)_{6}(\mathrm{OH})_{2}+x \mathrm{TiO}_{2}= & \mathrm{CaTiO}_{3}+(1-x) \mathrm{Ca}_{10}\left(\mathrm{PO}_{4}\right)_{6}(\mathrm{OH})_{2} \\
& +3 x \mathrm{Ca}_{3}\left(\mathrm{PO}_{4}\right)_{2}+x \mathrm{H}_{2} \mathrm{O}(1000 \mathrm{C})
\end{aligned}
$$

Thus a chemical bonding occurs if HA is deposited onto Ti surface at high temperature. This phenomenon in addition to the fact that $\mathrm{Ti}$ is considered to be the most biocompatible metal has prompted us to take up this study. It is clear from the in vivo measurements by earlier investigators that the major disadvantage of bulk apatite ceramics viz. their susceptibility for fatigue failure does not occur with $50 \mu \mathrm{m}$ thin coating of apatite on Ti substrates. There is no measurable difference in the fatigue strength of HA coated with $\mathrm{Ti}$ and uncoated $\mathrm{Ti}$. Push out tests on implants done on animals show that bone bonding to HA coatings is essentially the same as the HA bulk implants. This is not surprising but shows that from a bonding point of view no measurable difference exists between plasma sprayed apatite surface and sintered apatite surface.

Several methods have been tried earlier to deposit HA layers on the implants (Cook et al 1986; Ducheyne et al 1986). However, plasma spraying is generally preferred (Hench and Wilson 1991). Plasma sprayed HA coatings on titanium and titanium alloys are already being clinically used for orthopedic and dental implant purposes (Block et al 1987; Geesink et al 1987). Both crystallinity and purity of the source 
powder are inportant for the development of the pure crystalline coating. It is believed that an amorphous coating will be resorbed by the body and thus crystalline form is most desirable (Hastings et al 1989). The present paper describes the results of our investigation on plasma spraying of hydroxy apatite on $\mathrm{Ti}-6 \mathrm{Al}-4 \mathrm{~V}$ using a plasma torch assembly operating at ambient. The objectives were to optimize the process parameters to get good quality crystalline coatings which will be suitable for various promising applications like orthopedic/dentistry.

\section{Experimental}

Plasma spray torch assembly developed in our laboratory (operating in ambient) was used in this experiment. Figure 1 shows schematically the principles of plasma spraying. A d.c. arc is struck between the cathode and anode while a stream of gas passes through the arc, this results in the plasma formation with gas temperature as high as $>5000^{\circ} \mathrm{C}$ and speed of the gas approaching to that of the speed of sound. In a plasma torch the temperature of the plasma rapidly decreases as a function of the distance. Inside the arc the temperature is $>10000^{\circ} \mathrm{C}$ and few $\mathrm{cm}$ outside the electrodes the typical temperature is around $2000-3000^{\circ} \mathrm{C}$. The powder is suspended in a carrier gas which is fed into the plasma and impinged in a partially molten or plastic state towards the surface. The surface is then coated with a layer of powder. The quality of the coating is a complex problem which depends on powder properties and spray process parameter. While thermophysical properties are determined by powder morphology and their composition, melting of the powder particles is influenced by particle size, thermal conductivity, melting point, purity and spraying parameters. Since deposition of the molten particles and final coating quality are determined by spray parameters such as spray rate, gas type, flow, torch-base distance and nature of the substrate, all stages of the plasma spraying process are thus affected by the characteristics and properties of the powder.

Powders prepared in our laboratory were used for spraying. These powders were processed further and made suitable for plasma spraying. Moisture was removed from

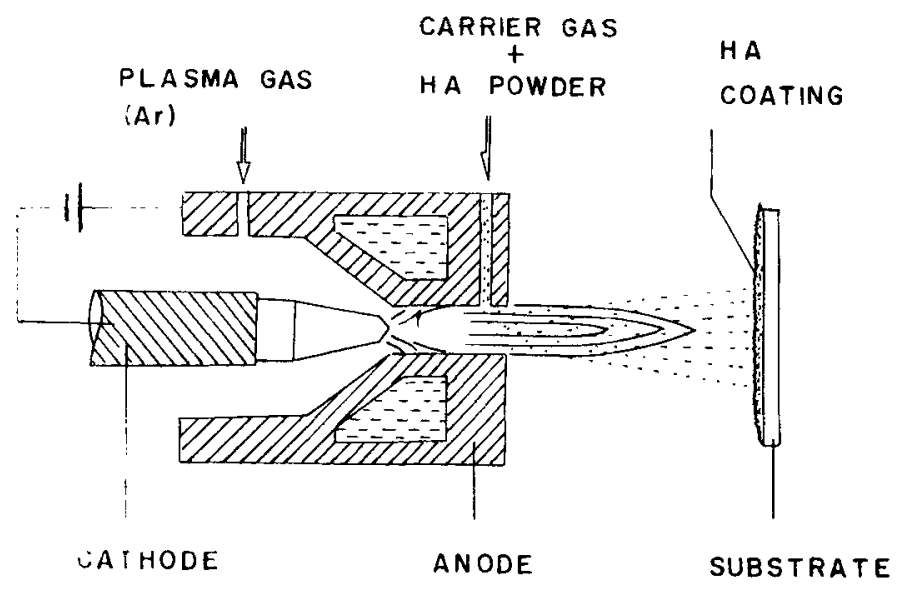

Higure 1. Schematics of a plasma spray process. 
Table 1. Typical plasma process parameters.

\begin{tabular}{ll}
\hline Arc voltage & $30 \mathrm{~V}$ \\
Arc current & $200 \mathrm{~A}$ \\
Plasma gas & $20 \mathrm{LPM}$ \\
Carrier gas & $8 \mathrm{LPM}$ \\
Hydrogen content & $1.5 \mathrm{LPM}$ \\
Torch-substrate distance & $\sim 65 \mathrm{~mm}$ \\
Powder size & -70 to +100 mesh \\
\hline
\end{tabular}

the powder prior to spraying by heating them in the microwave oven for $2 \mathrm{~min}$. Few coatings were made with Ar as a plasma as well as carrier gas. However, it was realized that it was essential to use hydrogen with the plasma medium in order to get the desired coatings using the present experimental configuration. Ti-6Al-4V plates of $1^{\prime \prime} \times 1^{\prime \prime}$ were used as substrates. Few cylindrical implants were also coated. The substrate plates were sand blasted and cleaned in acetone before use. Plasma flame from the torch was stabilized first and then the powder was fed with the carrier gas. Typical experimental parameters are shown in table 1.

The various parameters like plasma gas flow rates, torch-base distance, powder particle size were varied and the parameters were optimized to get HA content in the coating as per requirements given in the ASTM standard (ASTM Designation: F 1185-88). Coatings of varied thickness between 50 and $200 \mu \mathrm{m}$ were prepared and characterized by X-ray diffraction.

\section{Results}

As the process parameters were varied different phenomena were observed. For powder finer than specified in table 1, the powder particles evaporated, resulting in very low deposition rates. It was also difficult to make the powder flow into the plasma flame. The adhesion of the coating to the base was very poor. Coarse powder particles resulted in poor quality coatings due to low heat gained during transit through the plasma flame. Lower power levels (arc current) gave improper melting of the particles, which resulted in poor quality coatings in terms of adhesion. For torch-base distance less than the optimized one, it was observed that the substrates melted or warped. For longer distance the adhesion of the powder particles to the base was poor as the particles cooled during transit. The coatings obtained with the optimized parameters showed excellent adhesion as observed by the scratch test. By normal scratching the coating could not be removed from the substrate.

The sample coated by using Ar gas as a plasma as well as carrier gas showed $\beta$ TCP as the major phase and HA content in the coating was almost negligible. Most of the HA was transformed to $\beta$ TCP during transit through plasma flame. In addition to $\beta$ TCP other phase like tetracalcium phosphate was also observed in the coating. This is due to the reaction:

$$
\mathrm{Ca}_{10}\left(\mathrm{PO}_{4}\right)_{6}(\mathrm{OH})_{2} \rightarrow 2 \beta \mathrm{Ca}_{3}\left(\mathrm{PO}_{4}\right)_{2}+\mathrm{Ca}_{4} \mathrm{P}_{2} \mathrm{O}_{9}+\mathrm{H}_{2} \mathrm{O}
$$

This can be explained in the light of the thermal stability of $\mathrm{HA}$ as it is heated from room temperature. At $T>1050^{\circ} \mathrm{C} \mathrm{HA}$ is decomposed into $\beta$ and tetracalcium phosphates. At 


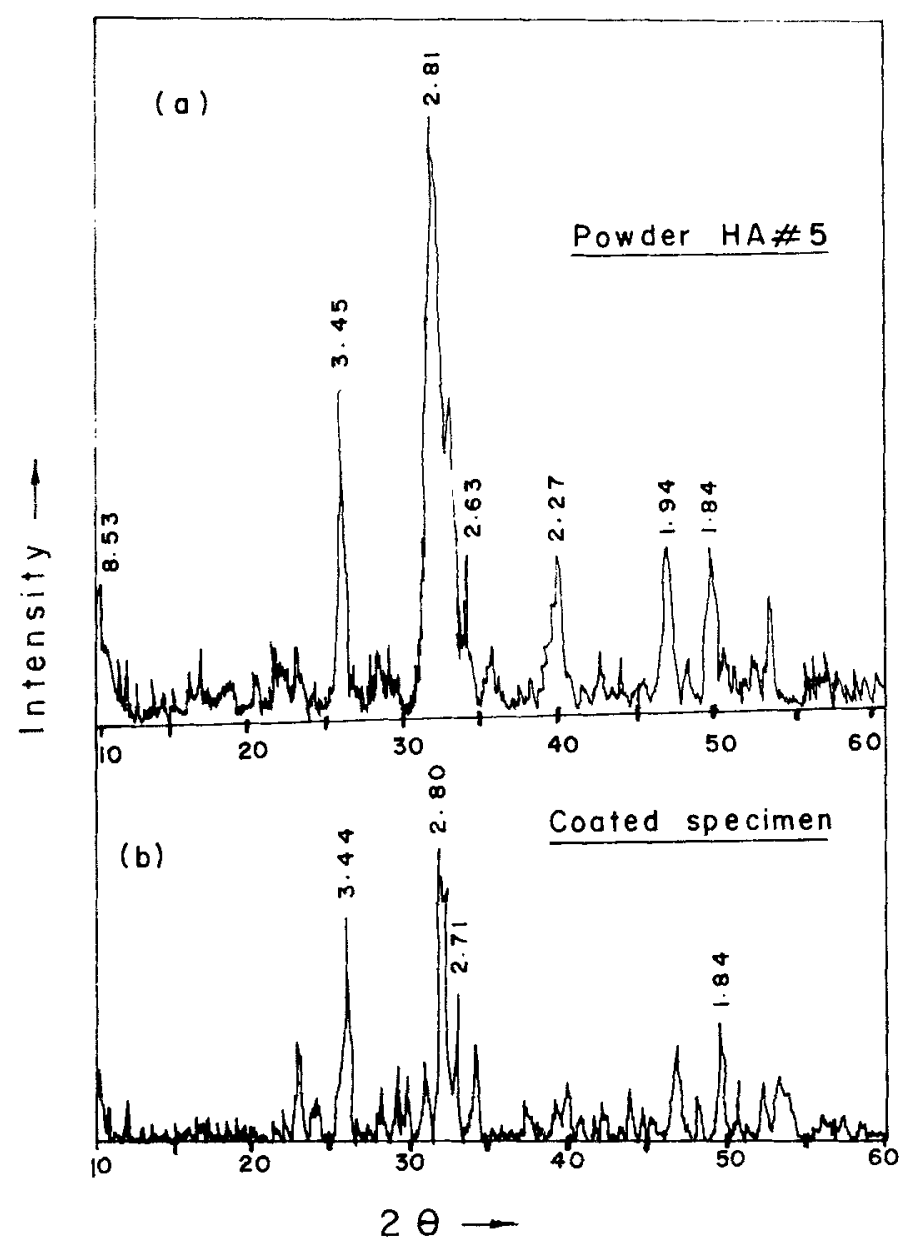

Figure 2. X-ray diffraction pattern of (a) powder HA \# 5 and (b) coated specimen.

$T>1350^{\circ} \mathrm{C}, \beta$ TCP transformed into $\alpha$ TCP, which is retained on cooling. X-ray diffraction on plasma sprayed coatings demonstrated that mixture of $\alpha$ and $\beta$ TCP and tetracalcium phosphate was obtained in the coatings. These different structures and compositions are known to alter biological reactions. This has not been specifically established for biomaterials but can be deduced from the behaviour of the biological apatites. Increased $\mathrm{Ca} / \mathrm{P}$ ratio and degree of crystallinity leads to greater stability of the biological precipitates in calcified tissues. It appears that calcium phosphate ceramics with $\mathrm{Ca} / \mathrm{P}$ ratios in the range of $1.5-1.67$ i.e. TCP and HA respectively yield the most beneficial tissue response. Williams (1985) discussed the importance of $\mathrm{Ca} / \mathrm{P}$ ratio in determining solubility and tendency for resorption in the body. All calcium phosphate ceramics biodegrade to varying degree in the following order: $\alpha$ TCP $>\beta$ TCP $>$ HA. Thus for decreasing rate of biodegradation, decreased $\beta$ TCP/HA ratios in biphasic calcium phosphates is desired. It is therefore necessary to control the phase state of a calcium phosphate bioceramic in addition to achieving precise compositional control (Hench 1991).

Phases formed at high temperature depend not only on temperature but also on the partial pressure of water in the surrounding atmosphere. With water present HA can be 


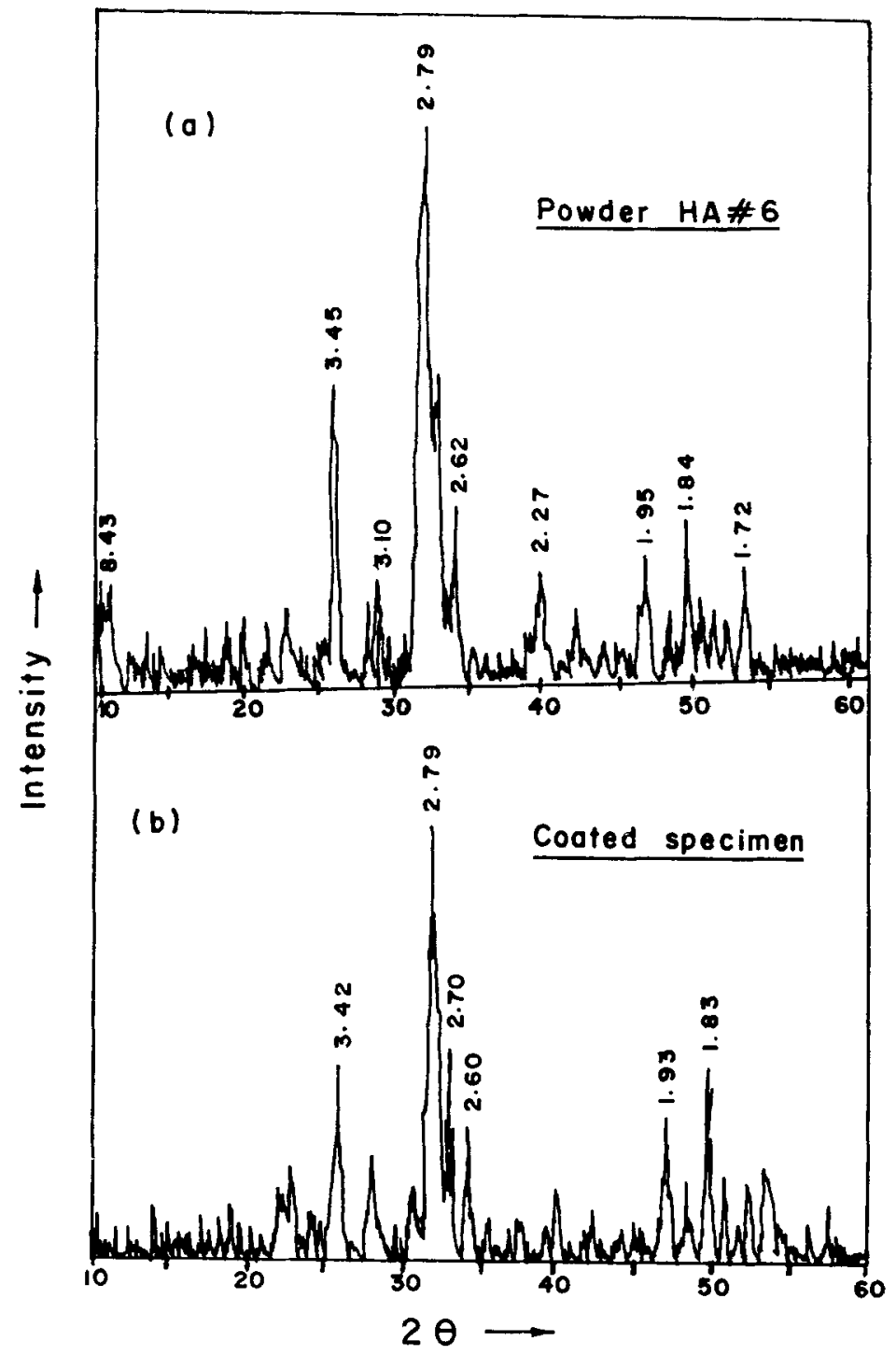

Figure 3. X-ray diffraction pattern of (a) powder HA \#6 and (b) coated specimen.

formed and is a stable phase up to $1360^{\circ} \mathrm{C}$. Without water tetra- and tricalcium phosphates are the stable phases. Temperature range of stability of HA increases with the partial pressure of water (Hench 1991).

X-ray diffraction results on the coatings obtained when a small amount of hydrogen was leaked in the plasma medium are shown in figures 2-3. XRD patterns of the powder are also included for comparison. All peaks characteristics of HA are reproduced in the patterns on coatings, confirming that HA is retained as a major phase after plasma spraying. The $\mathrm{X}$-ray diffraction patterns also indicate that the crystalline nature of the powder is retained after the plasma spraying operation. No additional treatment was necessary to achieve phase transformation of $\beta \mathrm{TCP}$ to $\mathrm{HA}$ and crystallinity in the coating. Thus our process is a single shot process of getting good quality coatings of HA on $\mathrm{Ti}-6 \mathrm{Al}-4 \mathrm{~V}$ required for medical applications. 


\section{Conclusions}

The process for depositing good quality coatings of $\mathrm{HA}$ on $71-6 \mathrm{Al}-4 \mathrm{~V}$ is described. The various plasma process parameters are optimized to achieve good quality coatings using plasma spray torch operating in ambient. The effect of these parameters on the coating quality is discussed. X-ray diffraction on the coatings showed that HA is retained in the coatings as per requirements.

\section{References}

Biock M S, Guerra L R, Kent J N and Finger I M 1987 Im. J. Oral. Maxillofac. Implants 2111

Cook S D, Kay J K, Thomas K A, Anderson P C, Reynolds M C and Jarcho J 1986 J. Dent. Res. 65222

De Groot K 1981 in Biocompatibility of clinical implant materials (ed) D F Williams (Boca Raton: CRC Press) vol. I p 199

De Groot K, Geesink R, Klein C P A T and Serekian 1987a J. Biomed. Mater. Res. 211375

De Groot K 1987b InterCeram 438

Ducheyne P, VanRaemdonck W, Heughebaert J C and Heughebaert M 1986 Biomaterials 797

Geesink R G T, De Groot K and Klein C P A 1987 Clin. Orthop. 225147

Hasting G W, Dailly D and Morrey S 1989 in Bioceramics: Proc. of 1st Int. bioceramic symposium (eds) H Oonishi, H Aoki and K Sawai (Tokyo: Ishiyaku Euro America Inc) p. 355

Hench L L 1991 J. Am. Ceram. Soc. 741487

Hench L L and Wilson J 1991 MRS Bull. XVI 62

Jarcho M 1981 Clin. Orthop. Rel. Res. 157259

Osborn J F 1987 Biomed. Tech. 32177

Smith R W and Novak R 1991 Powder Met. Inst. 23231

Stevenson J R, Legg H Solnick and Legg K O 1989 in Biomedical materials and devices (eds) J S Hanker and B L Giammara (Pittsburgh: Mat. Res. Soc. Symp. Proceedings, Materials Research Society) vol. 110 p 715

Williams D F 1985 in Biocompatibility of tissue analogs (eds) D F Williams (Boca Raton: CRC press) Vol. II, p 43 